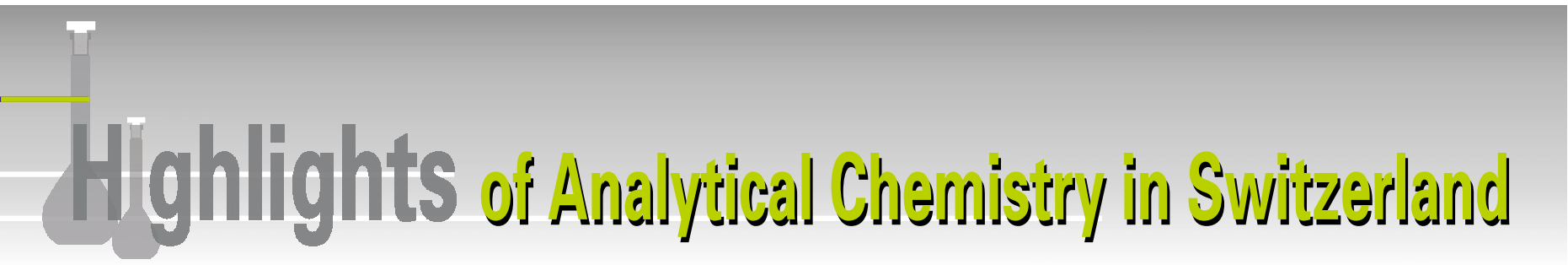

\section{The Mechanism of Chlorophyll Degradation in Plants}

\section{Stefan Hörtensteiner ${ }^{\star a}$, Thomas Müller ${ }^{\mathrm{b}}$, and Bernhard Kräutlerb}

${ }^{\star}$ Correspondence: Dr. S. Hörtensteinera ${ }^{\mathrm{a}}$, Tel: +41 4463482 82, Fax: +41 4463482 04, E-Mail: shorten@botinst.uzh.ch

anstitute of Plant Biology, University of Zurich, $\mathrm{CH}-8008$ Zurich; ' Institute of Organic Chemistry \& Centre of Molecular Biosciences, University of Innsbruck, A-6020 Innsbruck, Austria

Keywords: Antioxidants · Chlorophyll catabolites · Chlorophyll degradation $\cdot$ Leaf senescence $\cdot$ NCC

The autumnal coloration of deciduous trees is a most spectacular natural phenomenon and coincides with the disappearance of chlorophyll (Chl). The fate of Chl was unknown until 1991 when the first structure of a relevant Chl catabolite was elucidated by preparative HPLC, UV, MS, and NMR. ${ }^{[1]}$ Nowadays the path of Chl breakdown is largely resolved, including the structure elucidation of catabolites and the cloning of genes from catabolic enzymes. ${ }^{[2,3]}$

The structures of colorless Chl catabolites (NCCs) from leaves and fruits of various plant species exhibit a common backbone with an oxygenolytically opened chlorin ring. All remaining mesocarbons are saturated and as a consequence NCCs do not absorb visible light. These features indicate a largely conserved pathway of $\mathrm{Chl}$ breakdown within higher plants. However, different plant species also perform various peripheral modifications (R1-R3 in the Fig.), which increase polarity and allow deposition of NCCs inside the vacuole.

For a long time, Chl degradation during leaf senescence and fruit ripening was rationalized by the plant's aim to remobilize Chlderived nitrogen. Obviously this is not the case. Yet Chl metabolism is a prerequisite for nitrogen reuse from $\mathrm{Chl}$ binding proteins, accounting for about $20 \%$ of total cellular nitrogen. Mutants defective in several of the enzymatic steps show cell death phenotypes and accumulation of photo-reactive intermediates of $\mathrm{Chl}$ degradation. Thus, Chl breakdown is a detoxification process. NCCs seemed to be waste products without function, but recently they were shown to be potent antioxidants, which might contribute to the viability of ripe fruits, such as apples or pears. ${ }^{[4]}$

Received: April 14, 2008

\section{References}

[1] B. Kräutler, B. Jaun, K. Bortlik, M. Schellenberg, P. Matile, Angew. Chem., Int. Ed. 1991, 30, 1315.

[2] W. Mühlecker, K. H. Ongania, B. Kräutler, P. Matile, S. Hörtensteiner, Angew. Chem., Int. Ed. 1997, 36, 401.

[3] S. Hörtensteiner, Annu. Rev. Plant Biol. 2006, 57, 55.

[4] T. Müller, M. Ulrich, K. H. Ongania, B. Kräutler, Angew. Chem. 2007, 119, 8854

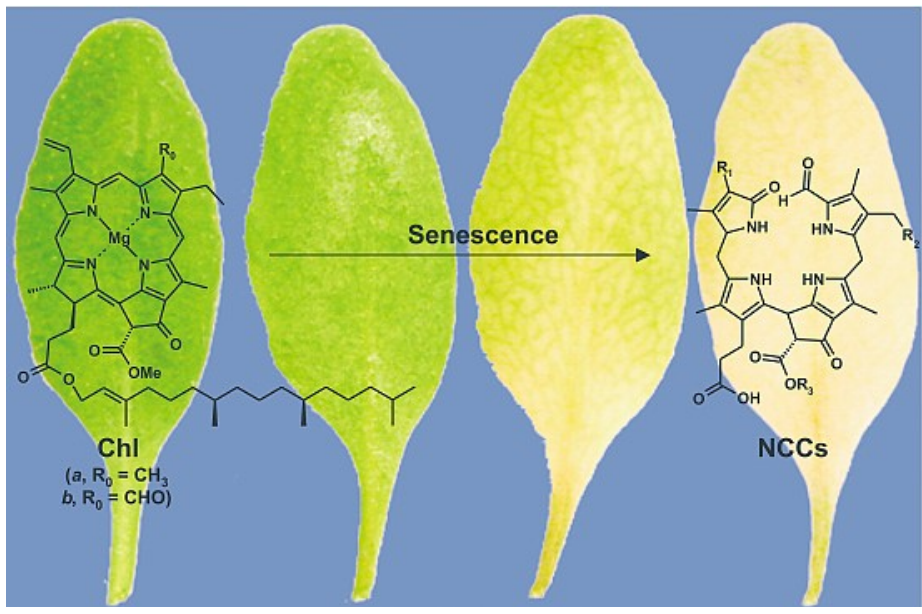

Major stages of leaf senescence in Arabidopsis thaliana (thale cress). The structures of chlorophyll (Chl) and final degradation products (NCCs) are shown. R1-R3 are sites of modifications found in NCCs from different plant species.

Autumn leaves - a symphony in green, red, and yellow 